DOI: https://doi.org/10.15688/lc.jvolsu.2017.3.1

UDC 343.211

LBC 67.408 .0

\title{
DIFFERENTIATION OF CRIMINAL RESPONSIBILITY: CORRELATION WITH RELATED CONCEPTS
}

\author{
Lev L. Kruglikov \\ P.G. Demidov Yaroslavl State University, Yaroslavl, Russian Federation
}

Introduction: a range of debating points of criminal law related to the differentiation of criminal responsibility and related concepts are analyzed. The goals and objectives of the study are to identify the nature and more precise definition of the criteria of differentiating criminal responsibility, as well as to demarcate this category from such concepts as individualization and unification of responsibility. Methods used by the author are traditional for the legal science. Results: the features inherent in the differentiation of criminal responsibility are characterized. Special attention is paid to such a criterion as the nature of the social danger of the act, as well as to the parameters of its definition. The position of the Supreme Judicial Authority of Russia on the issues of determining the nature and degree of public danger of the offense the guilty person has committed is analyzed. The features demarcating the differentiation of criminal responsibility from its individualization are educed; the relationship between the differentiation and unification of criminal responsibility is characterized. The inaccuracy of the opposition of differentiating the responsibility to its integration is proved. Scope of application: the article may be useful for the theory of criminal law, the legislator, the interpretative activities of the Supreme Court of the Russian Federation and the practitioners. Conclusions: the author concludes about the necessity to classify the nature of social danger defined by the legislator with the help of all the characteristics of the basic elements of a crime as the most important criteria of the differentiation of criminal responsibility; about the expediency of specifying the recommendation given for this reason by the Plenum of the Supreme Court of the Russian Federation; about the fundamental differences between the differentiation of criminal responsibility and its individualization in a number of subjects, reasons, results and the order of related activities; about the dialectical contradiction between the process of the differentiation of criminal responsibility from its unification.

Key words: responsibility, criminal responsibility, individualization of responsibility and punishment, unification of responsibility, differentiation of criminal responsibility.

УДК 343.211

ББК 67.408 .0

ДИФФЕРЕНЦИАЦИЯ УГОЛОВНОЙ ОТВЕТСТВЕННОСТИ: СООТНОШЕНИЕ СО СМЕЖНЫМИ ПОНЯТИЯМИ

Лев Леонидович Кругликов

Ярославский государственный университет им. П.Г. Демидова, г. Ярославль, Российская Федерация

Введение: анализу подвергается круг дискуссионных проблем уголовного права, связанных с дифференциацией уголовной ответственности и смежными понятиями. Цели и задачи исследования состоят в выявлении сути и уточнении критериев дифференциации уголовной ответственности, а также размежевании этой категории с такими понятиями, как индивидуализация и унификация ответственности. Методы, 
используемые автором, привычны для юридической науки. Результаты: охарактеризованы признаки, присущие дифференциации уголовной ответственности. Особое внимание уделено такому ее критерию, как характер общественной опасности деяния, а также параметрам его определения. Проанализирована позиция высшего судебного органа России по вопросам определения характера и степени общественной опасности содеянного виновным. Выявлены признаки, отграничивающие дифференциацию уголовной ответственности от ее индивидуализации, охарактеризована связь между дифференциацией и унификацией уголовной ответственности. Обоснована неточность противопоставления дифференциации ответственности ее интеграции. Область применения: статья может быть полезной для теории уголовного права, законодателя, интерпретационной деятельности Верховного Суда РФ и практических работников. Выводы: автором сформулированы выводы о необходимости отнесения к числу важнейших критериев дифференциации уголовной ответственности характера общественной опасности, определенного законодателем с помощью всех признаков основного состава преступления; о целесообразности уточнения данной по этому поводу рекомендации Пленума Верховного Суда РФ; о принципиальных различиях между дифференциацией уголовной ответственности и ее индивидуализацией по кругу субъектов, основаниям, результатам и порядку соответствующей деятельности; о диалектическом противоречии между процессом дифференциации уголовной ответственности и унификацией таковой.

Ключевые слова: ответственность, уголовная ответственность, индивидуализация ответственности и наказания, унификация ответственности, дифференциация уголовной ответственности.

\section{Введение}

Иногда дифференциацию уголовной ответственности относят к процессам не только правотворчества, но и правореализации, объявляя ее критерием степени общественной опасности содеянного и виновного в нем лица [1, с. 9]. Подобное мнение, думается, неточно.

\section{О характере общественной опасности как критерии дифференциации уголовной ответственности}

Прежде всего при такой трактовке упускается из виду исходный для дифференциации критерий - характер общественной опасности деяний и деятеля. Опираясь на справочные издания [11, с. 398], отметим, что дифференциация - это разделение, расчленение целого (здесь - ответственности) на различные части, формы и ступени [4, с. 58-60]. Соответственно первоочередной задачей при формировании законодателем системы санкций за различные виды преступлений (убийство, грабеж, изнасилование, лжесвидетельство и т. д.) выступает «определение вида, форм ответственности, и в первую очередь в зависимости от характера общественной опасности соответствующего вида преступления» $[4$, с. 58-60]. При этом деяния сопоставляются по их качественным особенностям, параметрам, не всегда удачно, однако, выделяемым на практике.
Так, в абз. 3 п. 1 Постановления Пленума Верховного Суда РФ от 22 декабря 2015 г. (№ 58) «О практике назначения судами Российской Федерации уголовного наказания» говорится, что «характер общественной опасности преступления определяется уголовным законом и зависит от установленных судом признаков состава преступления. При учете характера общественной опасности преступления судам следует иметь в виду прежде всего направленность деяния на охраняемые уголовным законом социальные ценности и причиненный им вред» [8].

Занятая Пленумом позиция не является безукоризненной. Нельзя, например, не учитывать множественности видов объектов. В науке их подразделяют и по вертикали, и по горизонтали. Какой из них следует взять для определения характера общественной опасности преступления?

Мы полагаем, что во всех случаях значимым является основной объект, под которым в теории понимают то общественное отношение (интерес), ради охраны которого создавалась соответствующая уголовно-правовая норма (например, жизнь - в составе убийства, отношения собственности - в составе разбоя) [5, с. 46; 12, с. 24-25]. Данный объект обязателен для любого состава преступления. Без его нарушения или поставления в опасность (реальную) соответствующее посягательство невозможно [12, с. 24-25]. При включении в состав преступления дополнительно- 
го объекта (то есть отношения (интереса), неизбежно нарушаемого или поставляемого в опасность при совершении преступления данного вида и потому защищаемого попутно с отношением, определяющим сущность такого посягательства, хотя и заслуживающего охраны с помощью самостоятельной нормы [12, с. 25]) указанный объект также влияет на характер общественной опасности деяния.

Кроме того, не меньшую значимость имеет и такой особо не выделяемый Пленумом критерий характера общественной опасности, как форма вины. Только по этому признаку различаются между собой убийство (ч. 1 ст. 105 УК РФ) и неосторожное причинение смерти (ч. 1 ст. 109 УК РФ). Санкции же за эти преступления существенно разнятся. Следовательно, различен и характер общественной опасности указанных преступных деяний. Не случайно неосторожное причинение смерти вынесено законодателем за рамки понятия убийства.

На наш взгляд, Пленум должен был разъяснить судам, что характер общественной опасности деяния зависит от закрепленных в уголовном законе (включая подразумеваемых им) признаков: а) основного, главного объекта преступления, б) вины в форме умысла или неосторожности, в) других признаков основного состава преступления. Это сориентировало бы правоприменителя на то, что характером опасности в первую очередь задаются квалификация преступления и вид применяемого судом наказания [5, с. 48].

На характер общественной опасности влияют и признаки специального субъекта преступления. Например, субъектами фальсификации доказательств по уголовному делу являются лицо, производящее дознание, следователь, прокурор или защитник. Только для них возможна уголовная ответственность по ч. 2 ст. 303 УК РФ. Таким образом, данный признак выступает обязательным, определяющим характер вредоносности описанного в ч. 2 ст. 303 вида посягательства. За незаконное получение кредита (по ч. 1 ст. 176 УК) несут ответственность индивидуальные предприниматели или руководители организации. Субъектом служебного подлога названы должностное лицо, а равно государственный или муниципальный служащий, не являющийся должностным лицом (ст. 292 УК).

В составе преступления того или иного вида ту же роль могут играть и другие признаки: характеризующие цель и мотив преступления (например, корыстная цель в составе кражи - ст. 158, мотив мести за оказание содействия администрации учреждения или органа уголовно-исполнительной системы ч. 1 ст. 321), способ (например, обман или злоупотребление доверием - ст. 159), свойства потерпевшего (ст. 131, 295, 318), признаки предмета преступления (ч. 1 ст. 228 и др.), орудий и средств, а также места совершения преступления (ст. 256, 264) и т. п. При альтернативных признаках (например, поддельные деньги или ценные бумаги - ч. 1 ст. 186, участие в банде или совершаемых ею нападениях - ч. 2 ст. 209 УК) характер общественной опасности определенного преступления имеет место при наличии хотя бы одного конститутивного признака, указанного в альтернативе с другими [5, с. 48-49].

\section{О недопустимости отождествления понятий дифференциации ответственности и ее индивидуализации}

Кроме того, непродуктивно понимание дифференциации ответственности, поглощающее процессы ее индивидуализации. Так, на взгляд А.М. Яковлева, важна реализация «дифференциации ответственности и индивидуализации наказания заранее, в самом законе (а не в ходе правоприменительной деятельности)» [13, с. 92].

Такая интерпретация ведет к смешению функций законотворчества и правоприменения. Дифференциация, решая те же задачи, что и индивидуализация, служит инструментом для законодателя и является принципом законотворчества. Согласно этому принципу законодатель, устанавливая уголовно-правовой запрет, должен разрешить целый комплекс проблем, возникающих применительно к диспозициям и санкциям соответствующих уголовно-правовых норм, как то: о необходимости уголовного наказания за это деяние; о возможности применения иных мер уголовно-правового характера за его совершение, а также 
освобождения от уголовной ответственности; о видах и пределах наказания, подлежащих включению в санкции; обязательности либо факультативности дополнительных наказаний; о конструировании квалифицированных составов и использовании определенных квалифицирующих признаков; о типе и виде санкций, а следовательно, и границах судейского усмотрения при применении конкретной уголовноправовой нормы и т. п.

Итак, сущность дифференциации ответственности заключается в «дроблении» последней, «дозировке», идет ли речь о дифференциации как о принципе, роде деятельности или о результате такой деятельности» $[4$, с. 61$]$.

Индивидуализация ответственности, как и дифференциация, также выступает инструментом уголовной политики, но уже в руках не законодателя, а правоприменителя. Воплощая волю последнего, суд, например, учитывает результаты осуществленной посредством правотворчества дифференциации ответственности, квалифицирует содеянное и определяет конкретные вид и меру ответственности в границах, заданных УК РФ, исходя уже из индивидуальной степени общественной опасности деяния и лица, его учинившего.

Пленум Верховного Суда РФ разъяснил в своем уже упомянутом постановлении (№ 58), что «степень общественной опасности преступления устанавливается судом в зависимости от конкретных обстоятельств содеянного, в частности от характера и размера наступивших последствий, способа совершения преступления, роли подсудимого в преступлении, совершенном в соучастии, от вида умысла (прямой или косвенный) либо неосторожности (легкомыслие или небрежность). Обстоятельства, смягчающие или отягчающие наказание (ст. 61 и 63 УК РФ) и относящиеся к совершенному деянию (например, совершение преступления в силу стечения тяжелых жизненных обстоятельств либо по мотиву сострадания, особо активная роль в совершении преступления), также учитываются при определении степени общественной опасности преступления» [8].

Таким образом, вопросы индивидуализации, будучи столь же важными, находятся в иной плоскости, нежели проблемы дифференциации ответственности. Их разрешение осу- ществляется иным субъектом (правоприменителем, а не законодателем), в другом порядке (путем правоприменения, а не законотворчества), на основании иного акта, оформляющего результаты (процессуальным актом, а не уголовным законом) и т. д.

Разграничениепонятий индивидуализации и дифференциации ответственности важно не только в теоретическом, но и в практическом (законотворческом) плане: уголовный кодекс должен включать весьма полные и четкие предписания, относящиеся к каждой упомянутой сфере - и дифференциации, и индивидуализации, не допуская их смешения [3; 5 , с. 14].

\section{Дифференциация ответственности и ее унификация}

В диалектическом единстве с дифференциацией ответственности находится унификация ответственности в уголовном праве, осуществляемая также законодателем [6]. В рациональных границах она столь же необходима. Например, в отличие от первоначальной редакции УК РСФСР 1960 г. его редакция от 1 июня 1994 г. содержала уже не две главы, посвященные преступлениям против собственности, а одну. Отказавшись от другой, законодатель тем самым отказался и от дифференциации уголовной ответственности за преступления подобного рода, произведенной с учетом формы собственности. Это решение нашло отражение и в УК 1996 г. (глава 21).

Законотворческая практика подтверждает то, что дифференциация и унификация развиваются в определенном смысле синхронно от процесса унификации (например, консолидация целого ряда деяний в главу о хозяйственных преступлениях советских УК) к дифференциации (обособление в отдельную главу экологических преступлений в УК 1996 г.), и наоборот (движение от использования «разномастных» квалифицирующих обстоятельств к «блоковому» принципу формирования круга квалифицирующих признаков [5, с. 15].

Некоторые авторы как синоним термина «унификация» употребляют лексическую единицу «интеграция». Например, Т.А. Лесниевски-Костарева полагает, что «в рамках правотворческого процесса дифференциация ответственности уравновешивается ее унификаци- 
ей, интеграцией» [7, с. 37-38]. Такое отождествление некорректно, несмотря на близость данных терминов. Интеграция - сведение к целому, объединение в целое каких-либо частей, элементов [2, с. 116]; унификация - устранение различий, обеспечение единообразия [9, c. $98 ; 10$, с. 498]. Интеграция лишь один из вариантов унификации; осуществлениепоследней возможно и иным образом [9, с. 107].

\section{Выводы}

На основании изложенного сформулируем несколько выводов:

1. Критерием дифференциации уголовной ответственности служит не только типовая степень, но и характер общественной опасности деяний, определяемый законодателем. Пленуму Верховного Суда РФ следовало бы обратить внимание судей на то, что названный критерий зависит от установленных уголовным законом и вытекающих из него а) основного объекта преступления; б) формы вины; в) других признаков основного состава преступления.

2. Дифференциация выступает инструментом деятельности законодателя и принципом поведения последнего. В соответствии с данным принципом законодатель, криминализируя деяние и дозируя ответственность за него, обязан решить комплекс проблем, касающихся диспозиций и санкций соответствующих уголовно-правовых норм.

Вопросы индивидуализации решаются в иной плоскости, нежели дифференциация ответственности. Они предполагают их разрешение иным субъектом (правоприменителем, а не законодателем); в другом порядке (путем правореализации, а не законотворчества); на основании иного акта (процессуальным актом, а не уголовным законом), оформляющим итоги. При этом учету подлежит индивидуальная степень общественной опасности преступления и виновного в нем лица.

3. Антиподом дифференциации ответственности в уголовном праве является ее унификация, предполагающая обеспечение единообразия в подходе к сходным ситуациям. В развитии уголовного законодательства указанные процессы уравновешивают друг друга.

\section{СПИСОК ЛИТЕРАТУРЫ}

1. Коробеев, А. И. Уголовно-правовая политика: тенденции и перспективы / А. И. Коробеев, А. В. Усс, Ю. В. Голик. - Красноярск : Изд-во Красноярского университета, $1991 .-240 \mathrm{c}$.

2. Краткий словарь иностранных слов / сост. С. М. Локшина. - М. : Советская энциклопедия, 1978. $-351 \mathrm{c}$.

3. Кругликов, Л. Л. Вопросы дифференциации ответственности в уголовном законодательстве / Л. Л. Кругликов // Реализация принципа справедливости в правоприменительной деятельности органов уголовной юстиции. - Ярославль : ЯрГУ, 1992. -С. 58-66.

4. Кругликов, Л. Л. Дифференциация ответственности в уголовном праве / Л. Л. Кругликов, А. В. Васильевский. - СПб. : Юридический центр Пресс, 2002. - 300 c.

5. Кругликов, Л. Л. Проблемы теории уголовного права : избранные статьи, 2002-2009 гг. / Л. Л. Кругликов. - Ярославль : ЯрГУ, 2010. -591 с.

6. Кругликов, Л. Л. Унификация в уголовном праве / Л. Л. Кругликов, Л. Е. Смирнова. - СПб. : Юридический центр Пресс, 2008. - 312 с.

7. Лесниевски-Костарева, Т. А. Дифференциация уголовной ответственности. Теория и законодательная практика / Т. А. Лесниевски-Костарева. M. : HOPMA, 2000. $-400 \mathrm{c}$.

8. Российская газета. $-2015 .-25$ дек.

9. Сенякин, И. Н. Специализация и унификация российского законодательства: Проблемы теории и практики / И. Н. Сенякин. - Саратов : Изд-во Саратовского университета, 1993. - $194 \mathrm{c}$.

10. Словарь русского языка. В 4 т. Т. 1 / под ред. А. П. Евгеньевой. - М. : Русский язык : Полиграфресурсы, 1999. $-702 \mathrm{c}$.

11. Советский энциклопедический словарь / гл. ред. А. М. Прохоров. - М. : Советская энциклопедия, 1987. $-1600 \mathrm{c}$.

12. Фролов, Е. А. Объект уголовно-правовой охраны и его роль в организации борьбы с посягательствами на собственность : автореф. дис. ... д-ра юрид. наук / Фролов Евгений Алексеевич. - Свердловск, $1971 .-53 \mathrm{c}$.

13. Яковлев, А. М. Принцип социальной справедливости и основания уголовной ответственности / А. М. Яковлев // Советское государство и праBо. - 1982. - № 3. - С. 86-94.

\section{REFERENCES}

1. Korobeev A.I., Uss A.V., Golik Yu.V. Ugolovnopravovaya politika: tendentsii i perspektivy [Criminal and Legal Policy: Trends and Prospects]. Krasnoyarsk, Izd-vo Krasnoyarskogo un-ta, 1991. 240 p. 
Л.Л. Кругликов. Дифференциация уголовной ответственности: соотношение со смежными понятиями

2. Lokshina S.M., ed. Kratkiy slovar inostrannykh slov [A Short Dictionary of Foreign Words]. Moscow, Sovetskaya entsiklopediya Publ., 1978.351 p.

3. Kruglikov L.L. Voprosy differentsiatsii otvetstvennosti v ugolovnom zakonodatelstve [The Issues of Responsibility Differentiation in the Criminal Law]. Realizatsiya printsipa spravedlivosti $v$ pravoprimenitelnoy deyatelnosti organov ugolovnoy yustitsii [Implementation of the Principle of Justice in Law-Enforcement Activity of Legal Justice Bodies]. Yaroslavl, Izd-vo YarGU, 1992, pp. 58-66.

4. Kruglikov L.L., VasilevskiyA.V.Differentsiatsiya otvetstvennosti v ugolovnom prave [Differentiation of Responsibility in the Criminal Law]. Saint Petersburg, Yuridicheskiy tsentr Press, 2002. 300 p.

5. Kruglikov L.L. Problemy teorii ugolovnogo prava: izbrannye statyi, 2002-2009 gg. [Problems of the Theory of Criminal Law: Selected Articles, 20022009]. Yaroslavl, YarGU Publ., 2010. 591 p.

6. Kruglikov L.L., Smirnova L.E. Unifikatsiya v ugolovnom prave [Unification in the Criminal Law]. Saint Petersburg, Yuridicheskiy tsentr Press, 2008. $312 \mathrm{p}$.

7. Lesnievski-Kostareva T.A. Differentsiatsiya ugolovnoy otvetstvennosti. Teoriya i zakonodatelnaya praktika [Differentiation of Criminal Responsibility.
Theory and Legislative Practice]. Moscow, NORMA Publ., 2000. 400p.

8. Rossiyskaya gazeta, 2015, Dec. 25.

9. Senyakin I.N. Spetsializatsiya i unifikatsiya rossiyskogo zakonodatelstva: problemy teorii $i$ praktiki [Specialization and Unification of the Russian Legislation: Problems of Theory and Practice]. Saratov, Izd-vo Sarat. un-ta, 1993. 194 p.

10. Evgenyeva A.P., ed. Slovar russkogo yazyka. $V 4$ t. T. 1 [Dictionary of the Russian Language. In 4 vols. vol. 1]. Moscow, Russkiy yazyk Publ.; Poligrafresursy Publ., 1999. 702 p.

11. Prokhorov A.M., ed. Sovetskiy entsiklopedicheskiy slovar [Soviet Encyclopedic Dictionary]. Moscow, Sovetskaya entsiklopediya Publ., 1987. 1600 p.

12. Frolov E.A. Obyekt ugolovno-pravovoy okhrany i ego rol v organizatsii borby s posyagatelstvami na sobstvennost: avtoref. dis. ... d-ra yurid. nauk [The Object of Criminal Legal Protection and Its Role in the Organization of Fight against Encroachments on Property. Dr. jurid. sci. abs. diss.]. Sverdlovsk, 1971. 53 p.

13. Yakovlev A.M. Printsip sotsialnoy spravedlivosti i osnovaniya ugolovnoy otvetstvennosti [The Principle of Social Justice and Grounds for Criminal Liability]. Sovetskoe gosudarstvo i pravo, 1982, no. 3, pp. 86-94.

\section{Information about the Author}

Lev L. Kruglikov, Doctor of Juridical Sciences, Professor, Head of the Department of Criminal Law and Criminology, P.G. Demidov Yaroslavl State University, Sovetskaya St., 14, 150000 Yaroslavl, Russian Federation, krugliko@uniyar.ac.ru.

\section{Информация об авторе}

Лев Леонидович Кругликов, доктор юридических наук, профессор, заведующий кафедрой уголовного права и криминологии, Ярославский государственный университет им. П.Г. Демидова, ул. Советская, 14, 150000 г. Ярославль, Российская Федерация, krugliko@uniyar.ac.ru. 